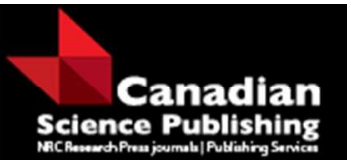

Canadian Journal of Forest Research

Revue canadienne de recherche forestière

\title{
Carbon sequestration and the optimal forest harvest decision under alternative baseline policies
}

\begin{tabular}{|r|l|}
\hline Journal: & Canadian Journal of Forest Research \\
\hline Manuscript ID & cjfr-2015-0222.R3 \\
\hline Manuscript Type: & Article \\
\hline Complete List of Authors: & $\begin{array}{l}\text { Asante, Patrick; University of Alberta, Department of Renewable Resources } \\
\text { Armstrong, Glen; University of Alberta, Department of Renewable } \\
\text { Resources }\end{array}$ \\
\hline Keyword: & $\begin{array}{l}\text { Baseline, Optimal harvest decision, Additionality, Landowner, Carbon offset } \\
\text { market }\end{array}$ \\
\hline \multicolumn{2}{|c}{} \\
\hline
\end{tabular}

\section{SCHOLARONE ${ }^{\text {m }}$}

Manuscripts 


\title{
Carbon sequestration and the optimal forest harvest
} decision under alternative baseline policies

\author{
Patrick Asante and Glen Armstrong
}

P. Asante ${ }^{1}$. Department of Renewable Resources University of Alberta, Edmonton, Alberta, Canada T6G 2H1

G. W. Armstrong. Department of Renewable Resources University of Alberta, Edmonton, Alberta, Canada T6G 2H1

\footnotetext{
${ }^{1}$ Corresponding author (E-mail: pasante@ualberta.ca. Tel.: +1(250)806-0005);

Ministry of Forests Lands and Natural Resources Operations, Victoria, BC, Canada

E-mail address for G.W. Armstrong: gwa@ualberta.ca
} 
1 Abstract: The choice of a baseline against which to evaluate changes in carbon stocks is

2 a critical component of any forest carbon offset market. In this paper we use a discrete

3 dynamic programming model and data from a lodgepole pine (pinus contorta) stand in

4 northeastern British Columbia, Canada, to demonstrate that different baselines have little

5 or no effect on optimal harvest decision, but can have a large impact on economic returns

6 to a landowner. The results reveal that the magnitude of the financial return to the

7 landowner is dependent on the starting conditions of both the predetermined baseline and

8 the proposed carbon offset project. The study also shows that when given the choice

9 between alternative baselines, a landowner will always choose a fixed baseline over a

10 business-as-usual (BAU) baseline.

11 Key words: Carbon offset market, Baseline, Optimal harvest decision, Additionality,

12 Landowner.

13 [Journal translation] 


\section{1}

\section{Introduction}

Carbon offset markets have been promoted as a method of allowing entities other than large emitters to contribute to a reduction in the rate of change of the amount of carbon dioxide $\left(\mathrm{CO}_{2}\right)$ and other greenhouse gases in the earth's atmosphere. The simple explanation is that if these other entities are able to sequester more greenhouse gases or to release less as a result of a change in practices, they may be able to earn carbon offset credits and sell them to large emitters, which will help the large emitters meet $\mathrm{CO}_{2}$ emission reduction obligations.

The first fully functioning compliance carbon market in North America is in the province of Alberta, Canada. A number of carbon offset quantification protocols have been developed in Alberta (Climate Change Central, 2011) including an afforestation protocol (now retracted for revisions) and a forest harvest practices protocol. In the recent past, there was considerable discussion about the development of a forest management protocol for the Alberta offset system: this discussion provided the impetus for the current study (AFGO, 2010a,b,c). The Alberta Forest Growth Organization (AFGO) organized a number of workshops in January, May and October of 2010 to discuss forest carbon offset system for the province of Alberta, Canada.

Protocols exist for carbon offsets from forest management projects in the voluntary carbon market, notably those of the Climate Action Reserve (Climate Action Reserve, 2010), the now defunct Chicago Climate Exchange (Chicago Climate Exchange, 2009), and Tree Canada (Tree Canada, 2009). These protocols set the rules about how carbon credits will be calculated and verified. Forest owners in North America may be able to sell carbon offset credits to emitters through various voluntary markets, ranging from easements with non-governmental organizations to negotiating directly with carbon dioxide $\left(\mathrm{CO}_{2}\right)$ emitters (Rudell et al., 2006). Carbon offset markets 
1 are developing and, in the voluntary market, forest carbon offsets are one of the most traded carbon

2 offsets, as revealed by an online survey of suppliers, brokers, and carbon credit accounting registries

3 from all over the world (Hamilton et al., 2007, 2008). However, forest carbon offsets present some

4 unique challenges for technical legitimacy, in particular the issues of additionality.

5

Additionality is key to the credibility of offsetting. We define additionality as the net amount of carbon sequestered, in excess of a predetermined baseline carbon stocks (or the net amount of carbon sequestered above what would have occurred, if no incentives for carbon management were present). Without additionality, a carbon offset project may actually cause an increase in greenhouse gas (GHG) levels, undermining the purpose (and credibility) of the carbon offset market. But demonstrating additionality can be difficult due to the subjectivity of project baselines. A baseline is the reference against which a project's carbon storage or GHG emission reductions are measured. Carbon sequestration levels or emission reductions in excess of the predetermined baseline level are considered additional and, thus, available for sale as offsets. Therefore, setting an accurate baseline is important in designing a credible forest carbon offset market.

Two main types of baselines are discussed in this study in relation to forest carbon offset projects. The first type is called the fixed baseline or a base year approach. This approach uses a fixed level of carbon stocks as the baseline: it could be the carbon stock at the beginning of the project. With this approach, stock changes are calculated by comparing changes of a proposed project's carbon stocks from one reporting period to the next; beginning from the base year (see panel a of Fig. 1). This type of baseline was the baseline of choice for the now defunct Chicago Climate Exchange, to determine additionality for managed forest offsets (Pearson et al., 2008)

The second type of baseline uses a counterfactual business-as-usual (BAU) approach. With this approach, stock changes are calculated by comparing changes in a project's carbon stocks to the 
1 changes assumed to occur had the project not been undertaken (see panel b of Fig. 1). This type of 2 baseline is used by the Climate Action Reserve to quantify net change in carbon stocks (Pearson et 3 al., 2008). Climate Action Reserve calculates additionality by subtracting periodic changes in 4 baseline's carbon stocks from periodic changes in project's carbon stocks.

5

6

7

8

9

\section{7}

\section{[Fig. 1 about here.]}

These baselines are by no means perfect as they have both been criticized. The fixed baseline approach has been criticized because it does not consider the amount of sequestration that would have occurred had the project not been implemented, creating uncertainty about whether the project "caused" any of the measured changes in sequestration levels. On the other hand, the BAU approach has been criticized because it relies on counterfactual model projections of carbon stocks made many years, sometimes decades, into the future. This creates a situation with information asymmetry, as nobody except the project proponent can know what he really would have done in the absence of a market, thus making it possible for the proponent to game the system. Therefore, neither baseline approach can be used to assess unequivocally whether, or to what extent, a project's carbon sequestration impact is additional to what would have occurred without the project (Beane et al.,2008).

We do recognize that there are other challenges such as managing for leakage and permanence that can affect the credibility of any forest carbon offset market, but our focus in this study is on additionality and baseline setting. We do not address leakage and permanence because their inclusion in this study will not impact the story we are trying to convey to our readers. Our 
1 purpose is to provide landowners, natural resource managers, policymakers and other interested

2 parties, some basic information on how the choice of a baseline will impact optimal harvest decision 3 or a landowner's decision to manage for carbon.

To facilitate the comparison of the different baselines, we used a stand level optimization approach because understanding stand level carbon dynamics is essential to addressing forest carbon sequestration. Many management actions that influence aggregate carbon stocks at the forest level are carried out at the stand level. In the forest economics literature, most of the stand level optimization models that consider carbon sequestration services (van Kooten et al., 1995; Spring et al., 2005a,b; Gutrich and Howarth, 2007; Asante et al., 2011) have used what we describe in this study as the fixed baseline approach to determine optimal harvest age. None, to the best of our knowledge have used the BAU baseline in the determination of optimal harvest age. The choice of harvest age is a fundamental decision in an even-aged silvicultural system. Delaying the harvest age allows stands to increase in volume, thereby storing more carbon (Asante et al., 2011; Asante and Armstrong, 2012). The work presented here is an extension of the previous work by Asante et al. (2011), which only considered the fixed baseline. In this study, both the fixed baseline and the BAU baseline were used to investigate the optimal harvest behaviour of a landowner. The primary contribution of this study to the literature on optimal economic rotation is the discovery that different baselines have little or no effect on optimal harvest decision, but can have a large impact on economic returns to a landowner. This knowledge can help decision makers in the design of a forest carbon offset market.

Similar to Asante et al. (2011), a dynamic programming model is developed to find the optimal stand management decision when both timber values and carbon sequestration services are considered. The choice of dynamic programming approach is based on the fact that it is a powerful 
1 approach to stand level optimization problems (Brodie and Haight, 1985). It allows one to solve 2 many different types of sequential optimization problems in a time frame for which a naive approach 3 would take exponential time. The forest stand in this dynamic programming problem is described in 4 terms of the initial and current age of the stand and the initial and current mass of carbon stored in 5 the dead organic matter (DOM) pool. DOM as used in this study is a generic term for all dead 6 organic compounds in a forest stand, including standing dead trees, down trees, coarse and fine 7 woody debris, litter and soil carbon. Carbon stored in long-lived products such as lumber is not considered in this model. Asante and Armstrong (2012) did consider the wood product pool using many of the same assumptions used in this paper. The effect of including the product pool on management decisions was small, and because this study is about comparing alternative baselines under the same treatment, the inclusion of the product pool would not impact the story we are trying to convey to our readers. Therefore, a decision was made to ignore the wood product pool for this study.

The dynamic programming model is used to address the following four main objectives:

(1) We want to understand if the choice of a baseline can be used as an incentive to encourage a landowner to increase forest carbon sequestration. That is, we want to know if the choice of a predetermined baseline can result in a longer optimal rotation age. We will answer this question by examining the sensitivity of optimal harvest age to carbon prices using different baseline policies.

(2) Using a fixed baseline, we showed in Asante et al. (2011) that the starting conditions of a stand in a proposed carbon offset project can have a big impact on financial returns to a landowner. Against this background, we want to investigate if the story would be the same with different baselines. This will be done by examining the sensitivity of the value of land, timber, and carbon 
1 sequestration services (LTCV, hereafter) to starting stand age.

2 (3) Thirdly, we want to be able to rank the alternative baselines in terms of their impact on financial 3 returns to the landowner.

4 (4) Finally, we want to investigate if the starting conditions of the predetermined baseline (not the 5 proposed project) can affect financial returns to the landowner.

7 2. Methodology

$8 \quad 2.1$ Timber yield and cost functions 2011).

The parameter values used to estimate the timber yield function are from Asante et al. (2011). They represent a lodgepole pine stand in northeastern British Columbia, Canada and all costs and revenues are expressed in 2011 Canadian dollars (CAD). To avoid repetition of how the parameters were derived in Asante et al. (2011), we would like to direct interested readers to Asante et al. (2011) for more detailed description of the derivation process. The timber yield, price and cost information is appropriate for lodgepole pine stand managed for lumber production in northeastern $\mathrm{BC}$ at the time this work was undertaken.

The merchantable timber volume grows according to a Chapman-Richards growth function: $V(a)=v_{1}\left(1-e^{-v_{2} a}\right)^{v_{3}}$ where $V(a)$ represents the merchantable timber volume in $\mathrm{m}^{3} /$ ha at age $a$ and $v_{1}, v_{2}$ and $v_{3}$ are parameters, which were set at 500.4, 0.027 and 4.003 respectively (Asante et al, 0 
1

2

$3 B(a)=b_{1}\left(1-e^{-b_{2} a}\right)^{b_{3}}$, where $\mathrm{B}(\mathrm{a})$ is the mass of carbon in $\mathrm{tC} /$ ha, stored in the living trees at

4 age $a$, and $b_{1}, b_{2}$, and $b_{3}$ are coefficients set at 198.6, 0.0253, and 2.64 respectively (Asante et al.,

5 2011). This function provides a reasonable representation of the tabulated biomass at different stand

6 ages from CBM-CFS3 (Kurz et al., 2009).

7

8

9

10

11

12

13

14

15

16

17

18

19

20

21

22

\subsection{Carbon pool dynamics}

The biomass pool (tC/ha) also grows according to a Chapman-Richards growth function:

From Asante et al. (2011), when there is no timber harvest, the DOM pool grows according to Eq. (1).

(1) $D_{t+1}=(1-\propto) D_{t}+\beta B(a)$

where $B(a)$ is the mass of carbon in $\mathrm{tC} / \mathrm{ha}$, stored in the living trees at age a as defined above, and $D_{t}$ is the mass of carbon in $\mathrm{tC} / \mathrm{ha}$, stored in the dead organic matter pool. The decay rate, $\propto$ and litter fall rate $\beta$, were estimated using the method of least squares to find the parameters $\propto$ and $\beta$ used in projections of CBM-CFS3 for the pine stand. The estimated parameters are $\propto=0.00841$ and $\beta=0.01357$.

Also in Asante et al. (2011), when timber harvest occurs, the mass of carbon removed from the site as merchantable timber volume is calculated as $\gamma V(a)$ where $\gamma$ is a constant used to convert wood volume to the mass of carbon stored in wood. We used $\gamma=0.2$ in this study. The carbon content of wood varies with tree species, although it is generally in the range of $200 \mathrm{~kg}$ $\mathrm{m}^{-3}$ (Jessome, 1977; van Kooten et al., 1995). This estimate is based on the calculation of carbon content in $1 \mathrm{~m}^{-3}$ of wood which is estimated as: $0.5 \mathrm{x}$ (dry weight of wood); where dry weight of wood $=($ specific gravity of wood $) \times$ (density of water). Density of water and specific gravity are assumed to be $1000 \mathrm{~kg} / \mathrm{m}^{-3}$ and 0.4 respectively. With timber harvest, the DOM pool 
1 grows according to Eq. 2.

2

(2) $D_{t+1}=(1-\propto) D_{t}+\beta B(a)-\gamma V(a)$

For the carbon market assumed here, the landowner is paid (pays) for annual changes in a project's total ecosystem carbon (TEC) stocks in excess (deficit) of the annual change in baseline quantity. Where, TEC is defined as the sum of carbon storage in the DOM pool (i.e. litter, dead wood and soil organic carbon) and the biomass pool (aboveground biomass and belowground biomass). This represents the total carbon storage in the forest stand. This method of carbon accounting is consistent with the carbon estimation methods outlined in the Intergovernmental Panel on Climate Change (IPCC) Good Practice Guidance for Land Use, Land-Use Change and Forestry (2003) report (Penman et al. 2003). With this approach, the annual change in project's TEC stocks can be defined as the sum of the carbon stock changes in the biomass and DOM carbon pools.

When there is no timber harvest, the change in biomass is defined by

$\Delta B(a)=[B(a+1)-B(a)]-\left[B^{b}(a+1)-B^{b}(a)\right]$, where $B^{b}(a)$ is the mass of carbon stored in the hypothetical projected biomass pool of a given baseline at stand age, $a$. With timber harvest, the age of the stand is set to 1 for the subsequent year, so the change in biomass becomes:

$\Delta B(a)=[B(1)-B(a)]-\left[B^{b}(a+1)-B^{b}(a)\right]$. The change in DOM for no harvest is given by: $\Delta D_{t}=\left[-\propto D_{t}+\beta B(a)\right]-\left[D_{t+1}^{b}-D_{t}^{b}\right]$, where $D_{t}^{b}$ is the mass of carbon stored in the hypothetical projected DOM pool of a given baseline at time, $t$. It is

$\Delta D_{t}=\left[-\propto D_{t}+B(a)-\gamma V(a)\right]-\left[D_{t+1}^{b}-D_{t}^{b}\right]$ for the harvest case. 
1

2

3

4

5

7

8

9

10

11

12

13

14

15

16

17

18

\subsection{Alternative Baselines}

Three different types of predetermined baselines were considered in this study: fixed baselines and two different types of BAU baselines. Baselines are generated based on the best estimate of how a forest landowner would manage the forest stand if there are no carbon sequestration incentives, i.e. when the price of carbon is set to $0 \mathrm{CAD} / \mathrm{tCO}_{2}$. The section that follows describes the selection process for the two types of BAU baselines.

\section{Selection process for $B A U$ baseline}

Two types of hypothetical projections of carbon sequestration levels are assumed for the BAU baseline in this paper, based on the best estimate of how a forest landowner would have managed the forest stand if there were no carbon sequestration incentives. The rationale is, with no carbon incentives (i.e. when price of carbon is $0 \mathrm{CAD} / \mathrm{tCO}_{2}$ ), a landowner will not delay the harvest age beyond the rotation age that maximizes the land expectation value (LEV) for timber only (i.e. Faustmann rotation age) or the rotation age at maximum sustained yield (MSY) timber volume. MSY is the largest yield that can be harvested which does not deplete the resource (timber) irreparably and which leaves the resource in good shape for future use. With carbon incentives (i.e. when price of carbon is not $0 \mathrm{CAD} / \mathrm{tCO}_{2}$ ), a landowner will delay the harvest age, thereby storing more carbon (van Kooten et al., 1995; Spring et al., 2005a,b; Gutrich and Howarth, 2007; Asante et al., 2011; Asante and Armstrong, 2012).

In this paper, the two hypothetical projections of carbon sequestration levels are referred to as maximum MSY and Faustmann baseline. The MSY and the Faustmann baselines are based 
1 on TEC stocks derived from a forest that is managed using an even-aged silvicultural system with

2 the objective of maximizing sustained yield timber volume and economic returns respectively.

3 To derive a BAU baseline, a three step procedure is followed.

4 (a) The rotation age is calculated. In the case of the MSY baseline, the volume maximization 5 sustained yield rotation age is the stand age where the mean annual increment (MAI) is 6 maximized, which is 88 years in this study. For the Faustmann baseline, the optimal economic 7 rotation is the stand age where the marginal return from allowing a stand to grow another year 8 equals the opportunity cost of the capital that would be generated from harvesting the current 9 crop and regenerating the site, thereby maximizing the value of the forest land (Pearse, 1990). 10 This paper used the discrete-time version of the Faustmann formula (Eq. 3) (Faustmann, 11 1849) to derive the Faustmann baseline.

(3) $L E V^{*}=\max _{t}\left[\frac{P^{w} V(a)-\left(F^{a}+F^{v} V(a)\right)-E(1+r)^{t}}{(1+r)^{t}-1}\right]$ For the data used, the optimal economic rotation age of the stand is 73 years

(b) The mass of carbon stored in the living trees is estimated using the biomass function: $B^{b}(a)=b_{1}\left(1-e^{-b_{2} a}\right)^{b_{3}}$, so that stand age $a$, runs from initial age to the age where harvest is optimized. The initial age is reset to 1 year in the year after harvest and the process is repeated.

(c) Finally, the DOM carbon stocks is then calculated for a combination of starting DOM stocks that runs from 0 to $500 \mathrm{tC} / \mathrm{ha}$. and starting stand age that runs from 0 to 250 years. The mass of carbon stored in the DOM pool is estimated using equations 1 and 2 where stand age $a$, runs from initial age to the optimal harvest age. The initial age is reset to stand age 1 after harvest and 
the process is repeated.

MSY or Faustmann baseline carbon stock is calculated as the sum of the biomass carbon stocks

$3\left[B^{b}(a)\right]$ and the DOM carbon stocks $\left[D^{b}\right]$. The projection of the TEC stocks for MSY and the 4 Faustmann baselines are presented in Fig. 2. Note that the baselines fluctuate because a single stand 5 is used in this study. A forest comprising many such stands would have a much smoother baseline.

6

\section{[Fig. 2 about here.]}

\subsection{Valuation of carbon}

The carbon market described in this paper pays landowners for the annual sequestration of $\mathrm{CO}_{2}$ in excess of the annual changes in the baseline quantity and requires payment for net annual release of $\mathrm{CO}_{2}$ in deficit of the annual changes in the baseline quantity. The price received per tonne of sequestered $\mathrm{CO}_{2}$ is the same as the price paid per tonne of released $\mathrm{CO}_{2}$. In this paper, a broad range of prices for $\mathrm{CO}_{2}\left(0,2,20\right.$ or $40 \mathrm{CAD} / \mathrm{t}$ of $\left.\mathrm{CO}_{2}\right)$ is used in sensitivity analysis. The range of prices chosen encompasses the range of observed prices including discounting occurs to account for the temporary nature of carbon sequestration in forests. It is conventional to express carbon prices in currency units per $\mathrm{CO}_{2}$ and stocks as tonnes of carbon $(\mathrm{tC})$. This practice of reporting is continued here, but for modelling purposes, equivalent prices for carbon $(\mathrm{CAD} / \mathrm{tC})$ is defined as $P^{C}=$

$3.67 \mathrm{P}^{\mathrm{CO}_{2}}$ because the molecular weight of $\mathrm{CO}_{2}$ is approximately 3.67 times the atomic weight of C. 
1

2

3

4

5

6

7

8

\subsection{The Model}

The basic assumption of the model is that a forest landowner is participating in a hypothetical carbon market where the landowner is paid for carbon sequestered by the forest and pays when carbon is released. In this market, it is assumed that the landowner behaves like a rational landowner (i.e. profit maximizing firm), in the sense of "neoclassical economics" and not in the sense of "behavioral economics," which considers psychological insights into human behavior to explain economic decision-making. In this market, the landowner's goal is to manage the forest for timber production and carbon sequestration in a manner that earns maximum discounted financial return. For simplicity, we also assume in this model that the only decision available to the landowner is either to "harvest" or "delay the harvest age" in order to maximize the combined returns of both timber values and carbon sequestration services (van Kooten et al., 1995; Spring et al., 2005a,b; Gutrich and Howarth, 2007; Asante et al., 2011; Asante and Armstrong, 2012).

We would like to acknowledge that there are several silvicultural techniques such as fertilization, herbicide treatment etc. that can be employed by a landowner to increase forest carbon sequestration, but we chose not to consider these silvicultural techniques, because it is beyond the scope of the study. We did not also consider these techniques because Armstrong (2014) showed that it is extremely unlikely that at any reasonable discount rate, any silvicultural action beyond harvest makes economic sense in the Boreal Plain ecozone of Canada (which covers northeastern British Columbia). Finally, the inclusion of any of these techniques would not change the main conclusions of the study. And this is why:

1 With carbon incentives, Stainback and Alavalapati (2005) were able to show that applying herbicide or fertilizer to a slash pine plantation, will result in a shorter rotation age and higher economic returns when compared to a scenario without these treatments. Given these findings, we 
1 can assume that the optimal rotation age and the economic returns (in our study) will also change if

2 we use any of these silvicultural techniques. However, this change will equally affect all the

3 alternative baselines considered in this paper. With the same treatment, we expect the response to be

4 the same for all the alternative baseline scenarios, although, the magnitude of the change will depend

5 on the silvicultural technique. The difference in economic returns to the landowner is mainly due to

6 differences in baseline policies. Therefore, replacing the silvicultural technique will not change the

7 major conclusions in this study.

8 In this model, each rotation begins with the establishment of a stand on bare forest land and

9 ends with a clearcut harvest after a number of years of growth. The beginning of a new rotation

10 coincides with the end of the previous rotation. The cycle of establishment, growth, and harvest is

11 assumed to repeat in perpetuity. The decision problem is represented as a dynamic program, and

12 state variables are used to describe the system at each stage of the decision problem.

13

\section{Dynamic Programming Model}

The model developed here is a discrete backwards recursion dynamic programming model. The stages represent time, in one year time steps. The forest stand is described by a combination of four state variables, the age of the stand (years), the initial stand age (years), carbon stocks in the DOM pool (tC/ha) and the initial carbon stocks in the DOM pool (tC/ha). The initial conditions are necessary to index the baseline. There are 251 discrete one-year wide age classes, $j$, with midpoints $a_{j}=j, j=0,1, \ldots, 250$ years; there are 501 DOM classes, $i$, with midpoints $d_{i}=i, i=$ $0,1, \ldots, 500 t C / h a$; there are 16 initial age classes, $x$, with midpoints $a_{x}=10 x(\mathrm{tC} / \mathrm{ha}), x=$ $0,1,2, \ldots, 15$; and there are 51 initial DOM classes, $s$, with midpoints $d_{s}=10 s(\mathrm{tC} / \mathrm{ha}), s=$ $0,1,2, \ldots, 50$. Timber harvest volume and carbon stored in the biomass pool are calculated as a 
1 function of stand age.

2 Every year, a decision is made by the landowner whether to clearcut the stand or let it grow for

3 another year. Clearcutting yields immediate timber revenue. Both the clearcut and the leave 4 decisions will result in a change in TEC (i.e. change in project's TEC stock less the change in 5 baseline TEC stock) and the appropriate carbon credit or debit. If harvesting does occur (i.e., 6 decision, $k=1$ ) in stage $t$, it is assumed that replanting occurs immediately and the stand age is set 7 to 1 in stage $t+1$. If harvesting does not occur (i.e., decision, $k=0$ ) in stage t, the stand age is 8 incremented by one year in stage, $t+1$. The change in total ecosystem carbon, $\Delta C_{t i s x j k}$ at any given stage $t$, depends on current DOM class $i$, initial DOM class $s$, a current age class $j$, initial age class $x$, and harvest decision $k$. It

11 is the sum of the annual changes in project's DOM stocks less the annual changes in baseline DOM

12 stocks, and the annual changes in biomass stocks less the annual changes in baseline biomass stocks.

13 Where $d_{t i s}^{b}$ is defined as baseline DOM class $i$ given an initial baseline DOM class $s$ in stage $t$.

14 For the no harvest case:

(4) $\Delta C_{t i s x j 0}=B\left(\min \left(\left(a_{x j}+1\right), 250\right)\right)+B^{b}\left(a_{x j}\right)+d_{t i s}^{b}-B^{b}\left(\min \left(\left(a_{x j}+1\right), 250\right)\right)-\min \left(d_{t i s}^{b}+1,500\right)$

For the harvest case:

(5) $\Delta C_{t i s x j 1}=B(1)+B^{b}\left(a_{x j}\right)+d_{t i s}^{b}-\propto d_{t i s}-\gamma V\left(a_{x j}\right)-B^{b}\left(\min \left(\left(a_{x j}+1\right), 250\right)\right)-\min \left(d_{t i s}^{b}+1,500\right)$ The net harvest revenue for initial age $x$ and age class $j,\left(H_{x j}\right)$ is calculated as ( (6) $H_{x j}=\left(P^{W}-F^{v}\right) V\left(a_{x j}\right)-F^{a} E$.

20 Establishment costs are included here because it is assumed that reforestation is required, and 21 occurs, immediately after timber harvest. 

The stage return or periodic payoff $\left(N_{t}\right)$ is calculated as shown in Eq. 7. The payoff is given

2 an initial age class $(x)$ and for each of the possible harvest decisions $(k)$. If a stand is not harvested $3(k=0)$, the periodic payoff would be based on $\Delta C_{t i s x j 0}$ only. If the stand is harvested $(k=1)$, the 4 payoff includes payments or charges based on $\Delta C_{t i s x j 1}$ as well as the net revenue associated with 5 timber harvesting, processing, and reestablishment.

(7) $N_{t}=\{a, i, x, j, k\}= \begin{cases}P^{C} \Delta C_{t i s x j 0} & : k=0 \\ P^{C} \Delta C_{t i s x j 1}+H_{x j} & : \quad k=1\end{cases}$

In this analysis, it is assumed the objective at each stage, is to determine, for each possible 8 combination of starting stand conditions (i.e., initial stand age and initial DOM), stand age, and level 9 of DOM stock, the harvest decision that results in the maximum net present value of land and timber and carbon storage for the remainder of the planning horizon. The stages in this dynamic programming model correspond to the time periods in which decisions are made. It is a finite horizon, deterministic model with time $t$ measured in years.

Because discrete DOM classes are used, the projections from Eqs. 1 and 2 are converted to the proportion of the source DOM class area that moves into two adjacent target DOM classes. $l_{\text {sixjk }}$ is used to represent the lower target class, and $u_{s i x j k}$, the upper target class. $\rho_{\text {sixjk }}$ is calculated to represent the proportion that moves into the upper target class, and $\left(1-\rho_{\text {sixjk }}\right)$ as the proportion that moves into the target lower class. In the notation used here, $\lfloor y\rfloor$ indicates the floor of a real number $y$, i.e. the largest integer less than or equal to $y$. The fractional part of $y$ is indicated by $\langle y\rangle$ such that $y=\lfloor y\rfloor+\langle y\rangle$.

(8) $\quad l_{t i s x j 0}=\min \left(\left\lfloor(1-\alpha) d_{t i s}+\beta B\left(a_{x j}\right)\right\rfloor, 500\right)$

(9) $l_{t i s x j 1}=\min \left(\left\lfloor(1-\alpha) d_{t i s}+\beta B\left(a_{1}\right)-\gamma V\left(a_{x j}\right)\right\rfloor, 500\right)$ 
1

2

3

(10) $l_{\text {tisxjk }}=\min \left(l_{\text {tisjk }}+1,500\right)$

(11) $l_{\text {tisxj0 }}=\left\langle(1-\alpha) d_{s i}+\beta B\left(a_{x j}\right)\right\rangle$

(12) $l_{t i s x j 1}=\left\langle(1-\alpha) d_{s i}+\beta B\left(a_{1}\right)+\gamma V\left(a_{x j}\right)\right\rangle$

A weighted return is calculated from the target states associated with the harvest decision, $k$. For the no harvest decision, $k=0$,

(13) $W_{t i s x j 0}=\left(1-\rho_{\text {tisxj0 }}\right) R_{t+1}\left\{l_{t i s x j 0}, \min ((j+1) 250)\right\}+\rho_{i j 0} R_{t+1}\left\{u_{i j 0}, \min ((j+1) 250)\right\}$

For the harvest decision, $k=1$,

(14) $W_{t i s x j 1}=\left(1-\rho_{t i s x j 1}\right) R_{t+1}\left\{l_{t i s x j 1}, 1\right\}+\rho_{t i s x j 1} R_{t+1}\left\{u_{t i s x j 1}, 1\right\}$

The return for the last stage in the problem is initialized to zero

(15) $R_{T}\{i, j\}=0$

This assumption is justified on the basis that $T$ is large (500 years) and the discounted value of $R_{T}$ for any reasonable discount rate for this problem is near zero (e.g. the present value of $1 \mathrm{CAD}$ received 500 years in the future is $2.5 \times 10^{-11} \mathrm{CAD}$ given a $5 \%$ discount rate). The discount factor, $\delta=(1+r)^{-1}$, represents the relative value of a dollar received one year from now (given an annual discount rate of, $r$ ) to a dollar today. For this study, we chose a real discount rate, $r$, of $5 \%$ per annum: and for this analysis, $\delta=0.9528$. Mathematically, Soil Expectation Value or Net Present Value calculated in real or nominal terms is the same, as long as consistent prices and interest rates are used. That is, if real costs and benefits are used, then a real rate must be used.

Choosing an appropriate discount rate to evaluate long term forest carbon sequestration projects is difficult since there are several opinions on what constitutes an appropriate discount rate. One possibility is to use the social discount rate. The Treasury Board Secretariat in Canada 
1 (Treasury Board Secretariat, 2007) recommends a social discount rate of $8 \%$ with sensitivity rates of $23 \%$ and $10 \%$. We used a social discount rate of $5 \%$ because it is a fair value intended to reflect 3 society's marginal rate of substitution between consumption in different time periods. The rate also 4 represents the possibility that climate damages are positively correlated with market returns 5 (Boardman et al., 2008). The recursive objective function for this problem is given in Eq. 16.

(16) $R_{t}\{s, i, x, j\}=\max _{k} N_{t}\{s, i, x, j, k\}+\delta W_{t i s x j k}, \quad t=T-1, T-2, \ldots, 0$

The recursive objection function selects the harvest decision for each possible starting stage and for each possible combination of state variables that maximizes the net present value at each stage, assuming that optimal decisions are made in all subsequent stages. It calculates a return for each of the harvest decisions and selects the harvest decision that results in the maximum return as the optimal choice for the state combination in that stage.

Eq. 17 below modifies the stage return at time zero for stands of age 0 , and represents the land expectation value for each initial DOM class. This incorporates establishment costs for time zero. For subsequent stages, establishment costs are incorporated in Eq. 7.

(17) $\forall_{s i}: R_{0}\{s, i, 0\} \leftarrow R_{0}\{s, i, 0\}-E$

\section{Results and Discussion}

The results presented in this section were calculated using an implementation of the dynamic programming model programmed in MATLAB (Pratap, 2006). The optimal harvest decisions for a number of different carbon prices using alternative baseline policies are presented in

Table 1. The results show that for different carbon prices $\left(\boldsymbol{P}^{C \boldsymbol{O}_{2}}\right)$, the optimal harvest age is about 
1 the same for different baseline policies. Therefore, the choice of a baseline policy has very little

2 impact on the optimal harvest behaviour of a landowner. Put in another way, the choice of a baseline

3 will not make a difference in terms of GHG emission reduction benefits. A different baseline will not

4 cause a landowner to delay harvest or increase carbon sequestration, but as we will see later in the

5 results presented in Fig. 4 and Table 2, it can have a large impact on financial returns to a

6 landowner. The results presented in Table 1 also show that optimal harvset age increases with

7 increase in carbon price. These results are consistent with results from other studies that show that

8 carbon price can be used as an incentive to increase forest carbon sequestration (van Kooten et al.,

9 1995; Spring et al., 2005a,b; Gutrich and Howarth, 2007; Asante et al., 2011; Asante and 10 Armstrong, 2012).

11 In Table 1, the decision rule when $\mathrm{P}^{\mathrm{CO}_{2}}$ is $0 \mathrm{CAD} / \mathrm{tCO}_{2}$ corresponds to the case when

12 timber is the only value considered. $\mathrm{As}^{\mathrm{CO}_{2}}$ increases, the optimal harvest age also increases.

13 When $\mathrm{PCO}_{2}$ is $35 \mathrm{CAD} / \mathrm{tCO}_{2}$ or greater, the optimal decision is to never harvest (i.e. harvest 14 age is greater than 250 years).

15

16

17

18

19

20

21

22

\section{[Table 1 about here.]}

Fig. 3 summarizes the LTCV for the state space, for carbon prices of $0,2,20$, and 40 $\mathrm{CAD} / \mathrm{tCO}_{2}$ given a predetermined Faustmann baseline which has an initial stand age of 0 years and initial DOM carbon stocks of 370 tC/ha. The vertical axis in Fig. 3 represents starting DOM stocks (tC/ha) and the horizontal axis represents starting age (years). The contours indicate combinations of age and DOM states that have the same LTCVs and the region where LTCV is positive is shaded 
1 grey. In this analysis, a young stand refers to a stand that is 50 years old or younger, and a mature 2 stand refers to a stand that is older than 50 years.

3 Panel (a) in Fig. 3, represents the case where $\mathrm{P}^{\mathrm{CO}_{2}}=0$. Because carbon has no value, in this 4 case, the LTCV is independent of the amount of DOM stored. This means that at any given initial 5 stand age, the LTCV is the same irrespective of the initial DOM stocks. Fig. 3 also shows that a 6 landowner who begins with a younger stand will benefit more when provided with carbon 7 management incentives compared to a landowner who begins with a mature stand. This implies that 8 if a landowner starts with a young stand, the LTCV will increase if $\mathrm{P}^{\mathrm{CO}_{2}}$ increases. This effect is 9 more pronounced when carbon prices are high and starting DOM is low (e.g. below $300 \mathrm{tC} / \mathrm{ha}$ ). This 10 is consistent with the results presented in other studies that show that financial returns increase with 11 increasing $\mathrm{P}^{\mathrm{CO}_{2}}$ (van Kooten et al., 1995; Spring et al., 2005a,b; Gutrich and Howarth, 2007). As an 12 illustration, let us we consider a landowner who begins with a stand that is currently 50 years old 13 growing on a piece of land with initial DOM stock of $370 \mathrm{tC} / \mathrm{ha}$, the LTCV is estimated as 1,200 $14 \mathrm{CAD} /$ ha when $\mathrm{P}^{\mathrm{CO}_{2}}=0 \mathrm{CAD} / \mathrm{tCO}_{2}$. This value increases to $1,300 \mathrm{CAD} / \mathrm{ha}$ when $\mathrm{PCO}_{2}=$ $152 \mathrm{CAD} / \mathrm{tCO}_{2}$. At a $\mathrm{P}^{\mathrm{CO}_{2}}=20 \mathrm{CAD} / \mathrm{tCO}_{2}$, the $\mathrm{LTCV}$ further increases to $2,200 \mathrm{CAD} / \mathrm{ha}$ and at $\mathrm{P}^{\mathrm{CO}_{2}}$ $16=40 \mathrm{CAD} / \mathrm{tCO}_{2}$, the LTCV is $4,100 \mathrm{CAD} / \mathrm{ha}$.

17 18 19 22 years old with initial DOM stock of $370 \mathrm{tC} / \mathrm{ha}$, the LTCV actually declines from 8,300 CAD/ha
[Fig. 3 about here.]
21 declines when $\mathrm{P}^{\mathrm{CO}_{2}}$ increases. Notice that if a landowner begins with a stand that is currently 100

0 The same cannot be said when a landowner begins with a mature stand. The LTCV actually

21 
1 when $\mathrm{P}^{\mathrm{CO}_{2}}=0 \mathrm{CAD} / \mathrm{tCO}_{2}$ to $7,800 \mathrm{CAD} /$ ha when $\mathrm{P}^{\mathrm{CO}_{2}}=2 \mathrm{CAD} / \mathrm{tCO}_{2}$. It then decreases to 3,400

$2 \mathrm{CAD} /$ ha when $\mathrm{P}^{\mathrm{CO}_{2}}=20 \mathrm{CAD} / \mathrm{tCO}_{2}$, and finally to $3,300 \mathrm{CAD} /$ ha when $\mathrm{P}^{\mathrm{CO}_{2}}$ increases to 40

$3 \mathrm{CAD} / \mathrm{tCO}_{2}$. These findings contrasts with results from other studies which generally show an

4 increase in financial return when $\mathrm{P}^{\mathrm{CO}_{2}}$ is increased. Why is this happening? A possible explanation

5 for this behaviour is that younger stands grow faster and, therefore, sequester $\mathrm{CO}_{2}$ at a faster rate. If a

6 landowner starts with a young stand, the benefit associated with faster growing trees may be enough

7 to compensate for the carbon release charge associated with DOM decomposition, resulting in a net

$8 \mathrm{CO}_{2}$ storage and therefore an increase in LTCV when $\mathrm{P}^{\mathrm{CO}_{2}}$ increases. On the other hand if a

9 landowner starts with a mature stand, the carbon benefit associated with slower growing trees may

10 not be enough to compensate for the carbon release charge associated with DOM decomposition,

11 leading to a decrease in LTCV when $\mathrm{P}^{\mathrm{CO}_{2}}$ increases. The same general trend is observed when

12 either a predetermined fixed baseline or a predetermined MSY baseline is used.

13 Fig. 4 is used to rank the predetermined baselines in terms of how they contribute to 14 financial returns to the landowner. The results presented in Fig. 4 are based on three predetermined 15 baselines with an initial age of 0 years and initial DOM of $0 \mathrm{tC} / \mathrm{ha}$. The graphs were generated using $16 \quad \mathrm{P}^{\mathrm{CO}_{2}}=20$.

The results shown in Fig. 4 reveal that for any given starting condition of a project stand, the financial return to carbon management is higher when a predetermined Faustmann baseline is used compared to a scenario that uses a predetermined MSY baseline. As an illustration, consider a stand that is currently 100 year old stand with an initial DOM of $200 \mathrm{tC} / \mathrm{ha}$, for $\mathrm{P}^{\mathrm{CO}_{2}}=20 \mathrm{CAD} / \mathrm{tCO}_{2}$, the LTCV will be 2,000 CAD/ha when a landowner uses a predetermined Faustmann baseline and 1,500 $\mathrm{CAD} /$ ha when a landowner uses a predetermined MSY baseline. What is causing the difference? The 
1 difference in the results is due to the fact that the MSY baseline has more TEC stocks over time 2 compared to the Faustmann baseline as shown in Fig. 2 and therefore the difference between the 3 projects's TEC and the baseline TEC is less for the scenario that uses the MSY baseline, resulting in 4 lower LTCV.

5

6

7

8

9

8

9 20

[Fig. 4 about here.]

baseline, it will result in highest LTCV of 3,500 CAD/ha. This can be explained by the difference in carbon accounting methods employed. Whereas the periodic change in baseline carbon stocks is zero for the fixed baseline approach, it is not zero in the BAU baseline approach. The gives rise to a larger change in TEC stocks between the project's TEC stocks and the baseline TEC stocks for the fixed baseline scenario.

To clarify the results presented in Fig. 4 some of the findings are summarized in Table 2. The results presented in Table 2 clearly show that when given the choice, a landowner would prefer a fixed baseline to either a Faustmann baseline or an MSY baseline when provided with carbon management incentives. MSY baseline is the least preferred option. 1 Fig. 5 compares the financial returns to the landowner based on different starting conditions for four predetermined baselines at a carbon price of $\mathrm{P}^{\mathrm{CO}_{2}}=20 \mathrm{CAD} / \mathrm{tCO}_{2}$. And for the purposes of 
1 illustration, only the MSY baseline is presented here. The four predetermined baselines have initial

2 DOM stocks of $0 \mathrm{tC} / \mathrm{ha}, 200 \mathrm{tC} / \mathrm{ha}, 400 \mathrm{tC} / \mathrm{ha}$ and $500 \mathrm{tC} / \mathrm{ha}$ which are presented in the panels a, b, c 3 and d in Fig. 5 respectively.

4

The results presented in Fig. 5 suggest that the initial DOM stock of a predetermined baseline significantly affects economic returns to carbon management. The results show that a landowner is better off if he/she chooses a predetermined MSY baseline that has higher initial carbon stocks in the DOM pool. As an illustration, consider a project stand that is currently 100 years old and has an initial DOM stock of $200 \mathrm{tC} /$ ha and of $\mathrm{P}^{\mathrm{CO}_{2}}=20 \mathrm{CAD} / \mathrm{tCO}_{2}$, the LTCV is 1,000 CAD/ha if the landowner selects a predetermined MSY baseline that has an initial DOM stock of $0 \mathrm{tC} / \mathrm{ha}$. The LTCV increases to $6,000 \mathrm{CAD} / \mathrm{ha}$ if the landowner selects a predetermined MSY baseline with an initial DOM stock of $500 \mathrm{tC} / \mathrm{ha}$. The same general trend was observed with Faustmann and Fixed baselines.

With the type of carbon market considered here where a carbon credit is calculated as the product of $\mathrm{P}^{\mathrm{CO}_{2}}$ and the difference between the annual changes in the project's TEC stocks and the annual changes in the baselines TEC stocks, one will think that a higher initial carbon stocks in the DOM pool for a predetermined will result in lower financial returns, but the reverse is true. This is happening because, starting with a baseline with a larger stock of DOM will generally release a greater absolute quantity of $\mathrm{CO}_{2}$ to the atmosphere and therefore increases the absolute difference between the project's TEC stocks and the baseline TEC stocks. The larger the difference between the project's TEC stocks and the baseline TEC stocks, the larger the carbon offset credit and therefore the larger the financial return. Hence, a baseline with a high initial carbon stock in the DOM pool is good for the landowner represented in this model. Similar trends in the results were obtained by using a predetermined Faustmann baseline or a predetermined Fixed baseline. In all model runs, 
1 changing the starting conditions or the type of baseline did not impact the optimal harvest age.

2

3

4

\section{[Fig. 5 about here.]}

The general results presented in this study are limited to stand level analyses. We expect the results to be different if a similar study is carried out at the forest-level, because of the effect of interperiod flow constraints imposed on forest-level models. Future research should investigate how alternative silvicultural techniques could impact the choice of a baseline policy at the forest level. Answers to these questions would contribute to policy discussions and advance our understanding on forest carbon offset markets. Our results can also be expected to differ from other analyses because of the particular form of the carbon market we assume. In this analysis, we assume a hypothetical market where the landowner pays for emissions and gets paid for sequestration in the year of occurrence. Other market structures such as those based on a contracted amount of carbon storage at a particular point in time could lead to qualitatively different results. Finally, in this market, we assume the landowner behaves like a rational landowner, in the sense of "neoclassical economics" and not "behavioral economics". The results could be different if we assume behavioral economics.

\section{Conclusions}

A key factor in designing any credible forest carbon offset market is the choice of a credible baseline against which changes in carbon stocks can be measured. This paper was set out to determine how a rational landowner will behave when given the choice to participate in a forest carbon offset market that considers alternative baseline policies. The purpose is to provide 
1 landowners, natural resource managers, policymakers and other interested parties, some basic

2 information on how the choice of a baseline will impact optimal harvest decision or a landowner's

3 decision to manage for carbon. The following are the main conclusions from this study:

4 (1) Alternative baselines have little effect on optimal economic rotation age. With carbon price as an

5 incentive, the choice of a baseline did not lead to any noticeable difference in optimal economic

6 rotation age.

7 (2) The study also showed that irrespective of the baseline policy, the starting conditions of the 8 proposed carbon offset project have a big impact on financial returns to the landowner. It is 9 therefore advantageous for a landowner to start with a young stand.

(3) In terms of ranking the baselines, the fixed baselines approach produced the highest financial return to the landowner. This was followed by the Faustmann baseline and then the MSY baseline. Although we showed that alternative baselines have little effect on optimal decision to harvest, they have a large effect on financial return to the forest landowner. In effect, behaviour changes little, but the amount of carbon offset that an emitter can claim for the same management decision is significant.

(4) The starting conditions (i.e. initial DOM) of the baseline imposed on a landowner have a significant impact on the financial returns to carbon management. For the type of carbon accounting method considered in this paper, a landowner is better off starting with a baseline with a high DOM stock.

The efficacy of any mitigating project is determined by the extent to which the project activities lead to the GHG emission reduction benefits that are additional to the established baseline. That is the true social value of a carbon offset project is related to the difference 
1 between the time series of $\mathrm{CO}_{2}$ concentration in the atmosphere with the project, and what 2 would have been the case had the project not been undertaken. In this paper we have 3 demonstrated that the choice of a baseline will not make a difference in terms of GHG emission 4 reduction benefits, but can have a large impact on financial returns to a landowner for the same management decision. Therefore, when trying to decide on the most appropriate baseline type for a proposed carbon offset project, policy makers should ensure that proposed baselines do not lead to unreasonable increases in financial return to landowners without making sure landowners change their behaviour; since the choice of alternative baselines do not lead to noticeable

9 difference in GHG emission reduction or increase in carbon sequestration. Policy makers should ensure that baselines are not set too low for landowners to receive a windfall and be rewarded just for choosing a particular baseline. In contrast, a baseline should not be set too high to be a disincentive for landowners to participate in the offset carbon market. These baselines will have to be adjusted to ensure an even playing field. 


\section{References}

2 AFGO, 2010a. Afgo forest offsets workshop number 1, January 2010 recap. Available from

3 https://friresearch.ca/resource/afgo-forest-offsets-workshop-2010-recap [Accessed 29 January

4 2016].

5 AFGO, 2010b. Afgo forest offsets workshop number 2, May 2010 recap. Available from

6 https://friresearch.ca/resource/afgo-forest-offsets-workshop-2-may-2010-reca [Accessed 29 January

7 2016].

8 AFGO, 2010c. Forests and energy - growing towards a carbon neutral alberta. alberta forest

9 growth organization, Edmonton AB. Available from https://friresearch.ca/resource/forests-

10 and-energy- growing-towards-carbon-neutral-alberta-recap [Accessed 29 January 2016].

11 Armstrong, G.W. 2014. Considerations for boreal mixedwood silviculture: A view from the

12 dismal science. For. Chron. 90:44-49.

13 Asante, P., and Armstrong, G. W. 2012. Optimal forest harvest age considering carbon

14 sequestration in multiple carbon pools: A comparative statics analysis. J. Forest Econ.

$15 \quad 18: 145156$.

16 Asante, P., Armstrong, G. W., and Adamowicz, W. L. 2011. Carbon sequestration and the

17 optimal forest harvest decision: A dynamic programming approach considering biomass and

18 dead organic matter. J. Forest Econ. 17:3-17.

19 Beane, J., Hagan, J., Whitman, A., and Gunn, J. 2008. Forest carbon offsets: a scorecard for

20 evaluating project quality. Available from http://www.manometmaine.org [Accessed 17 August

$212009]$.

22 Boardman, A. E., Moore, M. A., and Vining, A. R. 2008. Social discount rates for canada.

23 Paper prpresent at Evidence-based regulatory decision making Ottawa. 
1 Brodie, J., and Haight, R. 1985. Optimization of silvicultural investment for several types of

2 stand projection systems. Can. J. For. Res. 18:188-191.

3 Chicago Climate Exchange, 2009. Forestry carbon sequestration protocol. Available from

4 https://www.theice.com/publicdocs/ccx/protocols/ [Accessed 24 April 2015].

5 Climate Action Reserve, 2010. Forest project protocol version 3.2. Available from

6 http://climateactionreserve.org/how/protocols/forest/ [Accessed 28 April 2015].

7 Climate Change Central, 2011. Approved alberta pprotocols. Available from

8 http://www.csaregistries.ca/albertacarbonregistries/home.cfm [Accessed 23 April 2015].

9 Faustmann, M., 1849. Calculation of the value which forest land and immature stands

10 possess for forestry. J. Forest Econ. 1, 7-44, reprinted in 1995.

11 Gutrich, J., and Howarth, R. B. 2007. Carbon sequestration and the optimal management of

12 New Hampshire timber stands. Ecol. Econ. 62 (3-4), 441-450.

13 Hamilton, K., Bayon, R., Turner, G., and Higgins, D. 2007. State of the voluntary carbon 14 market 2007:picking up steam. Ecosystem Marketplace.

15 Hamilton, K., Sjardin, M., Marcello, T., and Xu, G. 2008. Forging a frontier: state of the 16 voluntary carbon markets, 2008., $78 \mathrm{pp}$.

Jessome, A. P. 1977. Strength and related properties of woods grown in Canada. Forestry Tech. Report no. 21, Eastern Forest Products Laboratory, Ottawa, Canada.

19 Kurz, W., Dymond, C., White, T. M., Stinson, G., Shaw, G., Rampley, G. J., Smyth, C.,

20 Simpson, B.,Neilson, E., Trofymow, J., Metsaranta, J., and Apps, M. J. 2009. CBM-CFS3: A

21 model of carbon-dynamics in forestry and land-use change implementing ipcc standards. 
1 Ecol. Model. 220, 480-504.

2 Pearse, P., 1990. Introduction to forestry economics. University of British Columbia Press,

3 Vancouver, BC.

4 Pearson, R., Brown, S., and Andrasko, K. 2008. Comparison of registry methodologies for

5 reporting carbon benefits for afforestation projects in the united states. Environ. Sci. Policy 11,

6 490-504. Penman, J., Gytarsky, M., Hiraishi, T., Krug, T., Kruger, D., Pipatti, R., Buendia, L.,

7 Miwa, K., Ngara, T., Tanabe, K., Wagner, F., editors. 2003. Good practice guidance for land

8 use, land-use change and forestry. Intergovernmental Panel on Climate Change (IPCC),

9 National Greenhouse Gas Inventories Programme, Institute for Global Environmental

10 Strategies, Kanagawa, Japan. Available from

11 http://www.ipccnggip.iges.or.jp/public/gpglulucf/gpglulucf\%5Fcontents.htm.[Accessed 29

12 January 2016].

13 Pratap, R., 2006. Getting Started with MATLAB 7: a quick introduction for scientists and engineers.

14 Oxford University Press, New York, NY, USA.

15 Rudell, S., Walsh, M., and Kanakasabai, M. 2006. Forest carbon trading and marketing in the

16 united states. North Carolina Division of the Society of American Foresters.

17 Spring, D., Kennedy, J., and Mac Nally, R. 2005a. Optimal management of a flammable forest

18 providing timber and carbon sequestration benefits: an Australian case study. Aus. J. Agr. Res.

19 Econ. 49(3):303-320.

20 Spring, D. A., Kennedy, J. O. S. and Mac Nally, R. 2005b. Optimal management of a forested

21 catchment providing timber and carbon sequestration benefits: Climate change effects. Global 
1 Environ. Change 15 (3):281-292.

2 Stainback, G.A., and Alavalapati, J.R.R. 2005. Effects of carbon markets on the optimal

3 management of slash pine (Pinus elliottii) plantations. Southern J. Appl. For. 29 (1):27-32.

4 Treasury Board Secretariat, 2007. Canadian cost-benefit analysis guide: Regulatory proposals,

5 ottawa, on. Available from http://www.regulation.gc.ca/documents/gl-ld/analys/analystb-

$6 \quad$ eng.asp. [Accessed 30 January 2010].

7 Tree Canada, 2009. Forest and urban tree carbon project protocol. version 1.1. Available from

8 https://reecanada.ca/files/2313/4880/1893/CarbonProtocolEnglish.pdf[Accessed 28 April

$92015]$.

10 van Kooten, G. C., Binkley, C. S., and Delcourt, G. 1995. Effect of carbon taxes and subsidies

11 on optimal forest rotation age and supply of carbon services. Am. J. Agr. Econ. 77 (2):365-374.

12

13

14

15

16

17

18

19 


\section{$1 \quad$ List of Tables}

2 1. Summary of harvest age for different carbon prices using alternative baseline policies _...34

32 2. Summary of Land, timber, and carbon values (CAD/ha) by initial stand age and initial

4 DOM stocks given alternative baselines policies with initial stand age of 0 years and

5 initial DOM carbon stock of $0 \mathrm{tC} / \mathrm{ha}$. 
1 Table 1. Summary of harvest age for different carbon prices using alternative baseline policies.

2 The results are based on initial stand age of 0 years and initial DOM stocks of $370 \mathrm{tC} / \mathrm{ha}$.

\begin{tabular}{|c|c|c|c|}
\hline $\begin{array}{c}\mathrm{P}^{\mathrm{CO}_{2}} \\
\left(\mathrm{CAD} / \mathrm{tCO}_{2}\right)\end{array}$ & $\begin{array}{c}\text { Rotation age } \\
\text { (Fixed baseline) } \\
\text { (years) }\end{array}$ & $\begin{array}{c}\text { Rotation age } \\
\text { (Faustmann baseline) } \\
\text { (years) }\end{array}$ & $\begin{array}{c}\text { Rotation age } \\
\text { (MSY baseline) } \\
\text { (years) }\end{array}$ \\
\hline 0 & 73 & 73 & 73 \\
\hline 1 & 74 & 75 & 76 \\
\hline 2 & 75 & 76 & 77 \\
\hline 5 & 78 & 79 & 79 \\
\hline 10 & 84 & 84 & 85 \\
\hline 20 & 101 & 101 & 102 \\
\hline 30 & 139 & 139 & 139 \\
\hline 35 & $>250$ & $>250$ & $>250$ \\
\hline
\end{tabular}

3

4

5

6

7

8

9

10

11

12

13

14

15

16

17 
Table 2. Summary of Land, timber, and carbon values (CAD/ha) by initial stand age and initial

2 DOM stocks given alternative baselines policies with initial stand age of 0 years and initial DOM carbon stock of $0 \mathrm{tC} / \mathrm{ha}$. The results are based on $\boldsymbol{P}^{C \boldsymbol{O}_{2}}=20 \mathrm{CAD} / \mathrm{tC}$.

\begin{tabular}{ccccc}
\hline $\begin{array}{c}\text { Initial DOM } \\
\mathrm{tC} / \mathrm{ha}\end{array}$ & $\begin{array}{c}\text { Starting Age } \\
(\text { years })\end{array}$ & $\begin{array}{c}\text { MSY baseline } \\
(\mathrm{CAD} / \mathrm{ha})\end{array}$ & $\begin{array}{c}\text { Faustmann baseline } \\
(\mathrm{CAD} / \mathrm{ha})\end{array}$ & $\begin{array}{c}\text { Fixed baseline } \\
(\mathrm{CAD} / \mathrm{ha})\end{array}$ \\
\hline \multirow{2}{*}{100} & 50 & 1,100 & 1,200 & 3,300 \\
& 100 & 2,200 & 2,500 & 4,800 \\
& 200 & 4,900 & 5,100 & 7,100 \\
\cline { 2 - 5 } 200 & 50 & 0 & 100 & 2,100 \\
& 100 & 1,500 & 2,000 & 3,500 \\
& 200 & 3,500 & 4,000 & 6,000 \\
\hline
\end{tabular}

4

5

6

7

8

9

10

11

12

13

14

15

16

17

18

19

20 


\section{List of Figures}

1. Amount of offset credits (tC/ha) generated in hypothetical examples

2. Projection of total ecosystem carbon stocks for MSY baseline and the Faustmann baseline cases given an initial stand age of 0 years and initial DOM stocks of $370 \mathrm{tC} / \mathrm{ha}$. There is a different baseline for each of the different starting conditions

3. Land, timber, and carbon values (CAD/ha) by stand age and carbon stocks in the DOM pool for different carbon prices given a Faustmann baseline with initial stand age of 0 years and initial DOM carbon stocks of $370 \mathrm{tC} / \mathrm{ha}$

4. Land, timber, and carbon values (CAD/ha) by stand age and carbon stocks in the DOM pool given alternative baselines with initial stand age of 0 years and initial DOM carbon stock of $0 \mathrm{tC} / \mathrm{ha}$

5. Land, timber, and carbon values (CAD/ha) by stand age and carbon stocks in the DOM pool given a MSY baseline with initial stand age of 50 years and varying initial DOM carbon stocks

2

3

4

5

6

7

8 


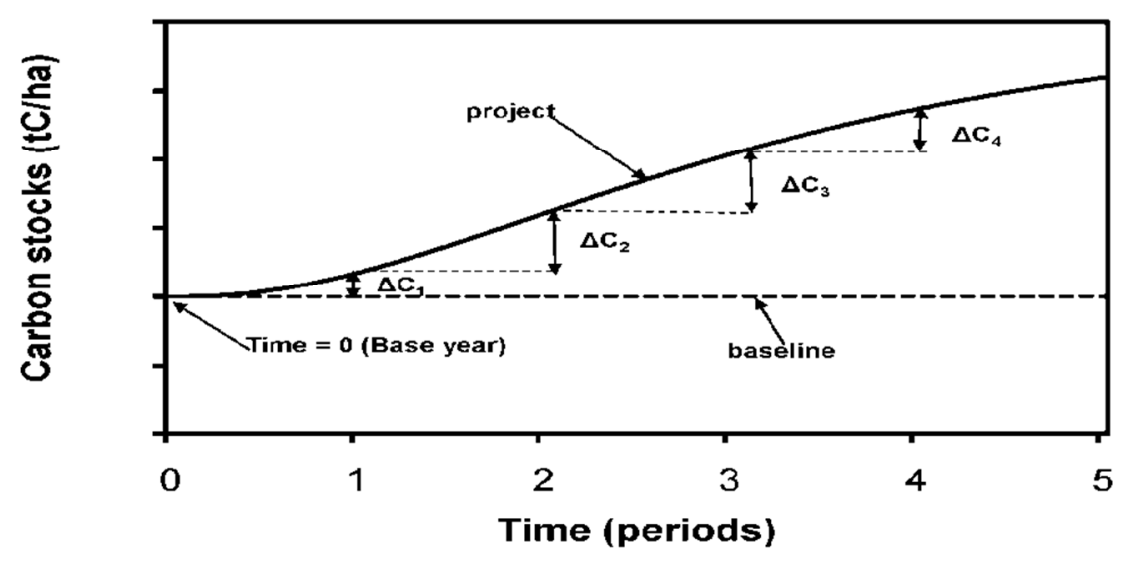

(a) Fixed baseline

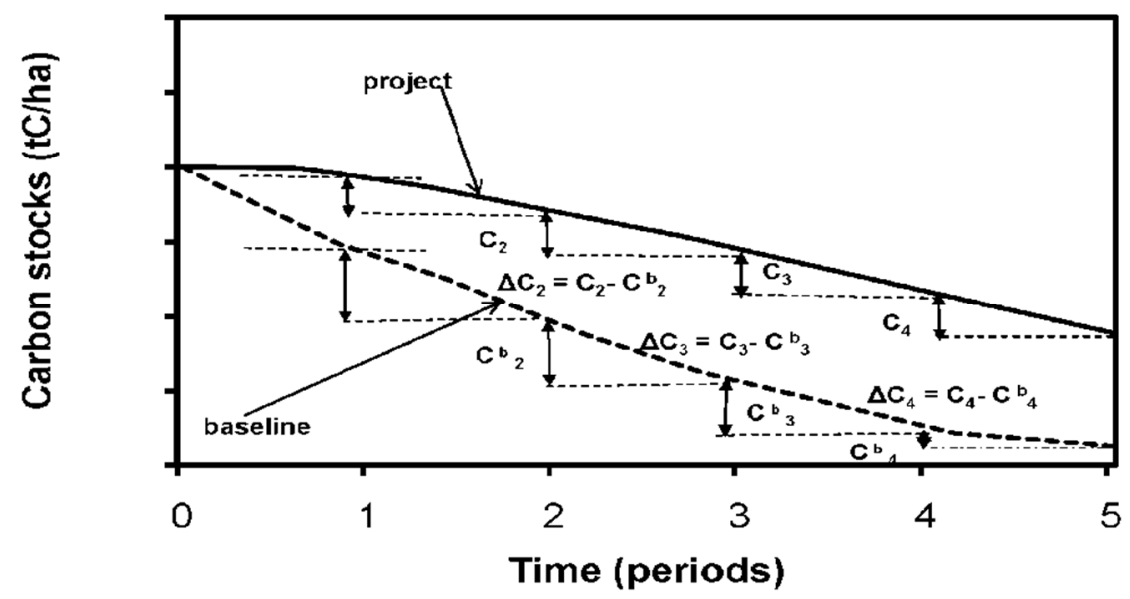

(b) Business-as-usual (BAU) baseline

1 Fig. 1. Amount of offset credits ( $\mathrm{tC} / \mathrm{ha}$ ) generated in hypothetical examples. Panel (a) shows the fixed

2 baseline approach and panel (b) shows the business-as-usual baseline approach. Under each approach, the 3 "additional" carbon that can be sold as offsets is represented by $\Delta C_{i}$ where $i$ is time in years. The BAU 4 approach requires projecting the amount of carbon that would have been on the project lands had the project 5 not occurred. The fixed baseline approach uses the carbon stocks at time zero (start of project) as the 6 baseline throughout the life of the project (although only increases in carbon stocks net those that have 7 already been sold as offsets are available for sale.) 


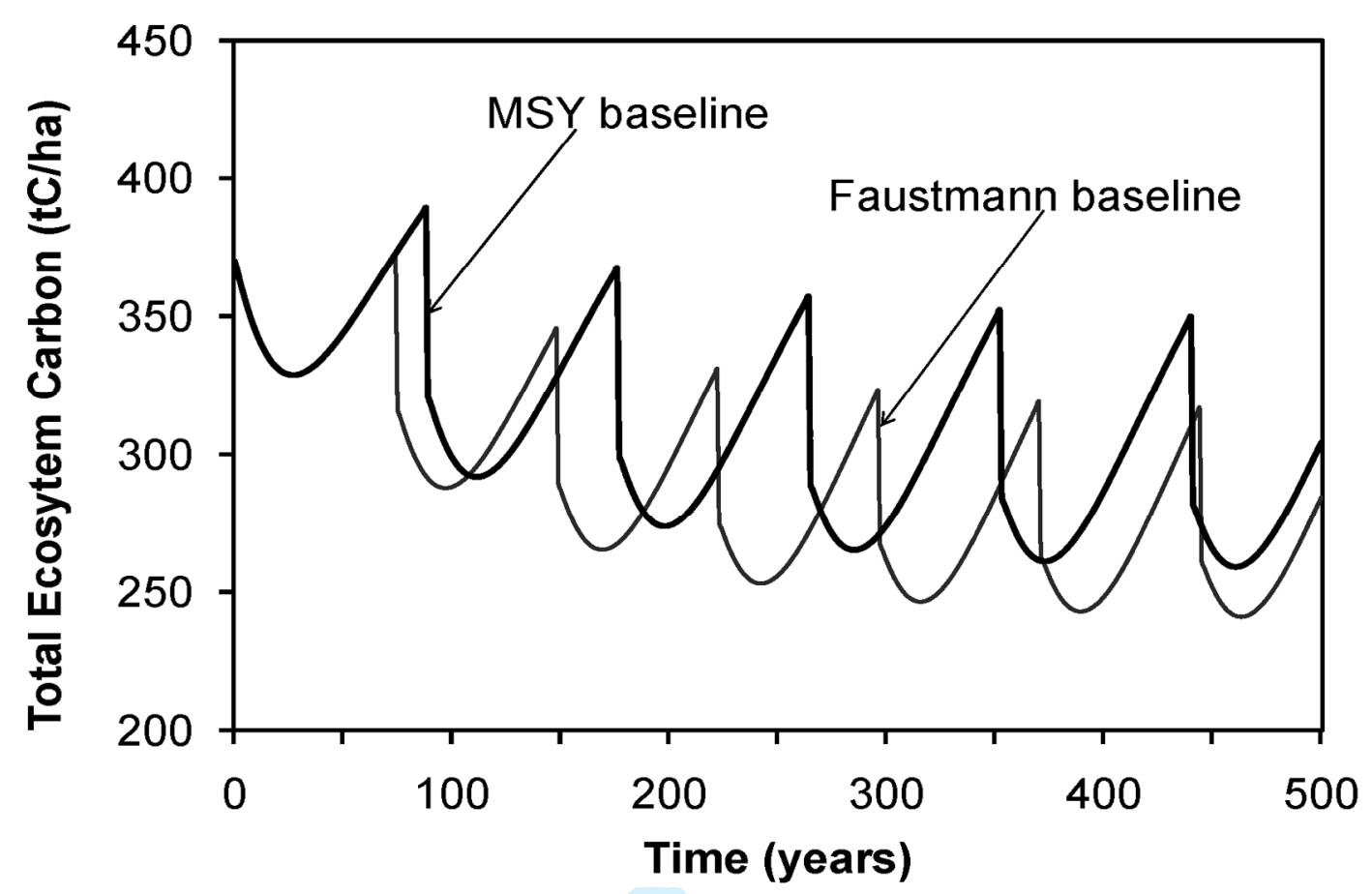

1 Fig. 2. Projection of total ecosystem carbon stocks for MSY baseline and the Faustmann baseline cases 2 given an initial stand age of 0 years and initial DOM stocks of $370 \mathrm{tC} / \mathrm{ha}$. There is a different baseline for 3 each of the different starting conditions

4 


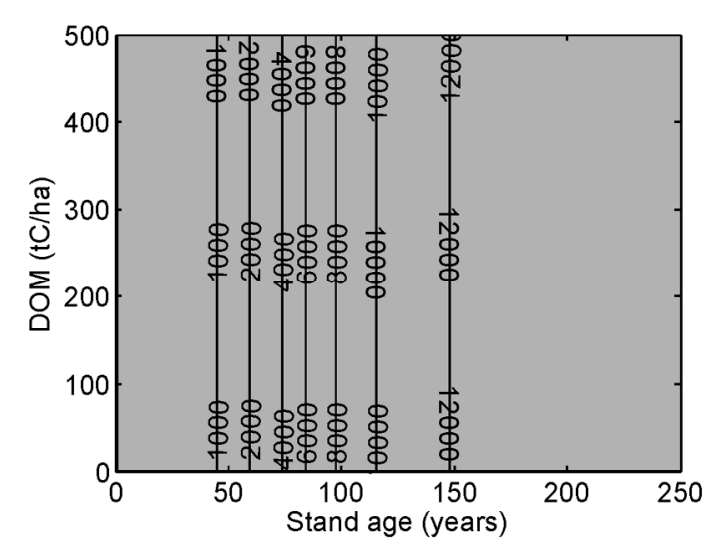

(a) $P^{C O_{2}}=0 C A D / t C$

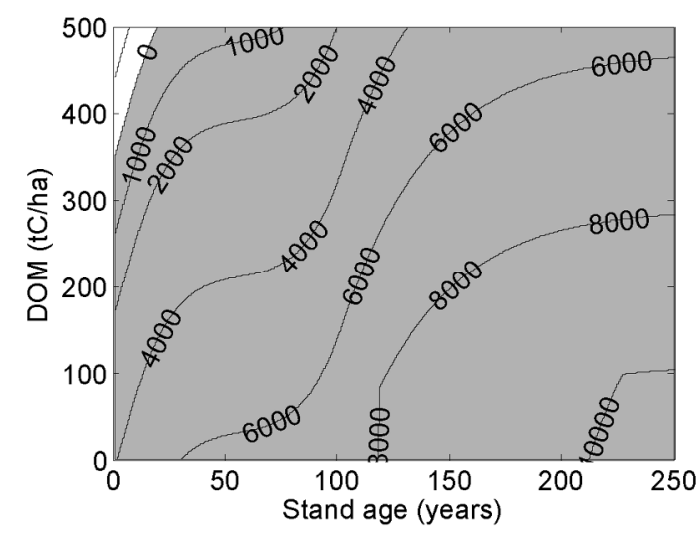

(c) $P^{C O_{2}}=0 \mathrm{CAD} / \mathrm{tC}$

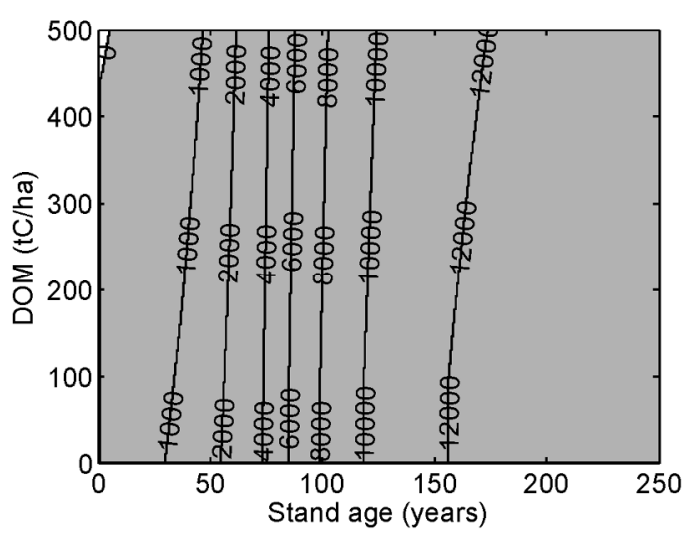

(b) $P^{\mathrm{CO}_{2}}=0 \mathrm{CAD} / \mathrm{tC}$

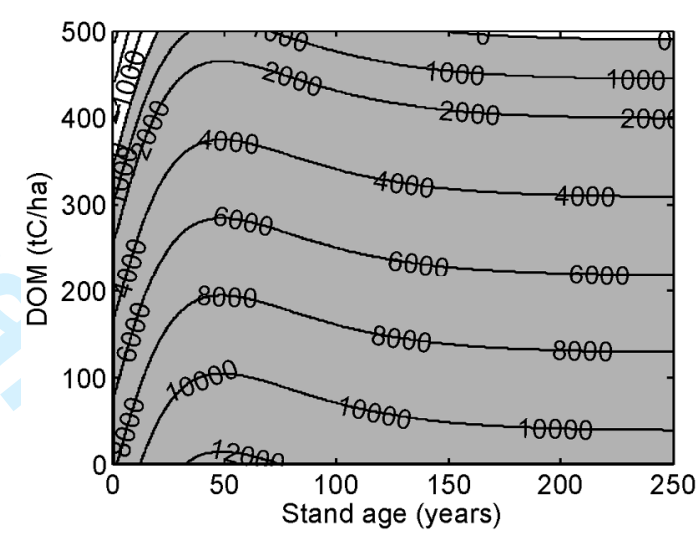

(d) $P^{C O_{2}}=0 C A D / t C$

1 Fig. 3. Land, timber, and carbon values (CAD/ha) by stand age and carbon stocks in the DOM pool for 2 different carbon prices given a Faustmann baseline with initial stand age of 0 years and initial DOM carbon 3 stocks of $370 \mathrm{tC} / \mathrm{ha}$. The contours indicate combinations of age and DOM states that have the same land, 4 timber, and carbon values. The region where LTCV is positive is shaded grey.

5 


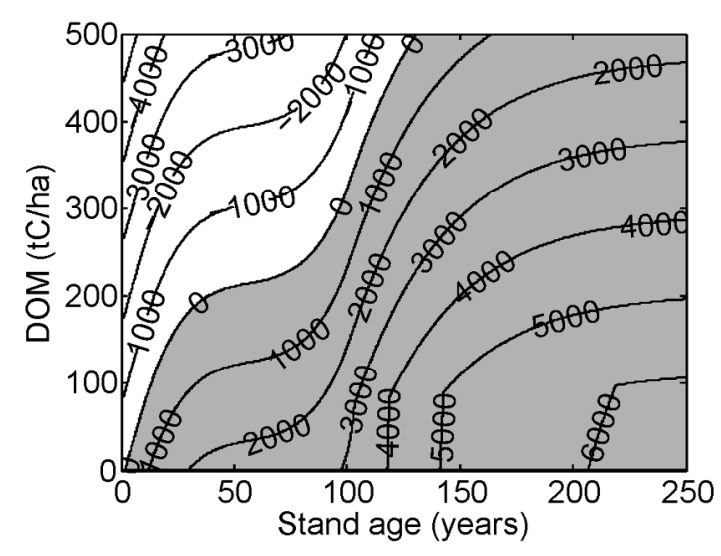

(a) MSY baseline

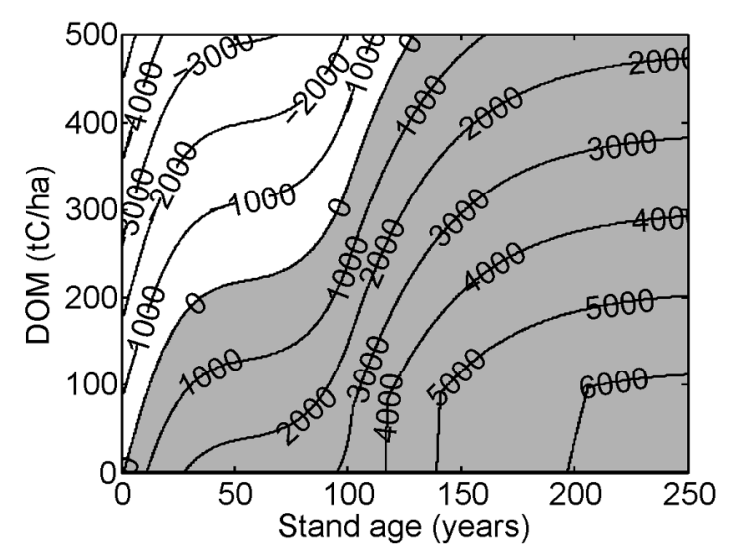

(b) Fausmann baseline

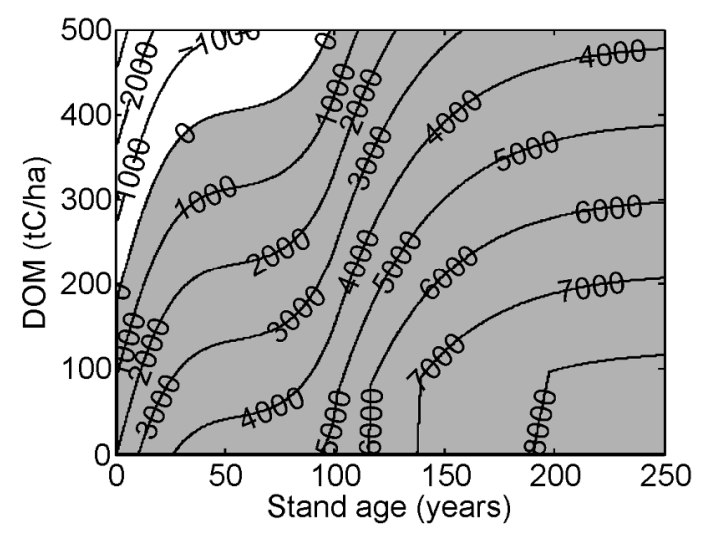

(c) Fixed baseline

1 Fig. 4. Land, timber, and carbon values (CAD/ha) by stand age and carbon stocks in the DOM pool given

2 alternative baselines with initial stand age of 0 years and initial DOM carbon stock of $0 \mathrm{tC} / \mathrm{ha}$. The results are

3 based on $P^{\mathrm{CO}_{2}}=20 \mathrm{CAD} / \mathrm{tC}$ and the contours indicate combinations of age and DOM states that have the

4 same LTCVs. The region where LTCV is positive is shaded grey.

5

6 


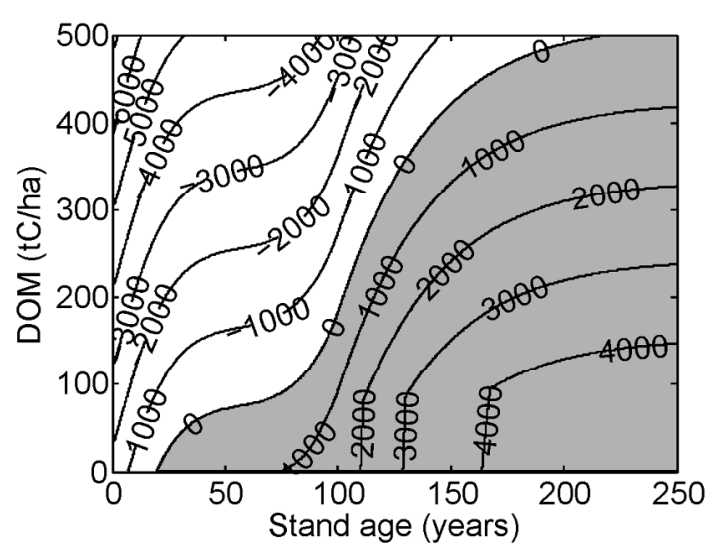

(a) MSY baseline with initial DOM stock of $0 \mathrm{tC} / \mathrm{ha}$ and initial age of 50 years.

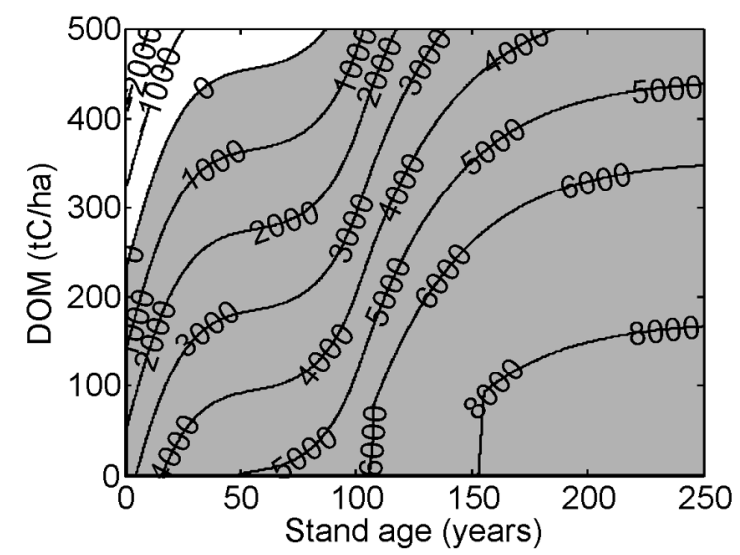

(c) MSY baseline with initial DOM stock of $400 \mathrm{tC} / \mathrm{ha}$ and initial age of 50 years.

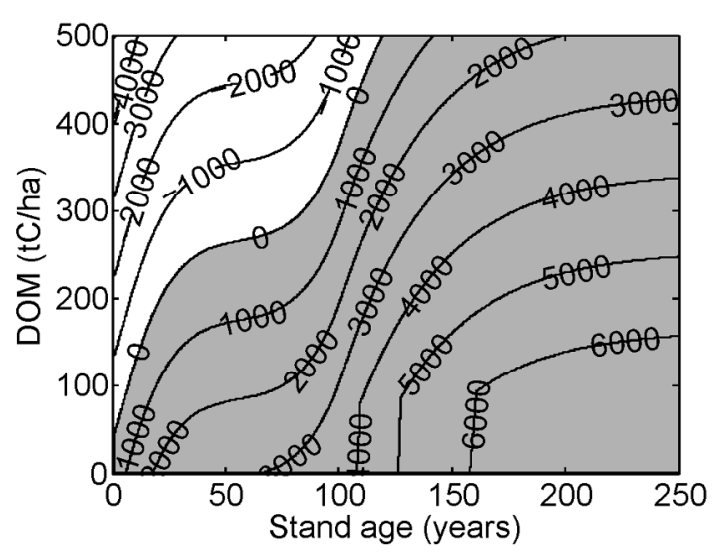

(b) MSY baseline with initial DOM stock of $200 \mathrm{tC} / \mathrm{ha}$ and initial age of 50 years.

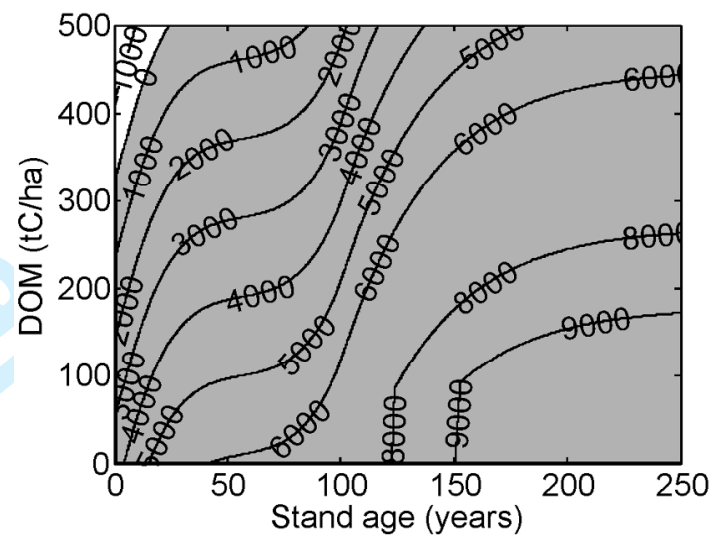

(d) MSY baseline with initial DOM stock of $500 \mathrm{tC} / \mathrm{ha}$ and initial age of 50 years.

Fig. 5. Land, timber, and carbon values $(\mathrm{CAD} / \mathrm{ha})$ by stand age and carbon stocks in the $\mathrm{DOM}$ pool given a MSY baseline with initial stand age of 50 years and varying initial DOM carbon stocks. The results are based on $P^{\mathrm{CO}_{2}}=20 \mathrm{CAD} / \mathrm{tC}$ and the contours indicate combinations of age and DOM states that have the same LTCVs. The region where LTCV is positive is shaded grey. 